\title{
HIV Testing Trends Among Persons with Commercial Insurance or Medicaid - United States, 2014-2019
}

\author{
Kirk D. Henny, $\mathrm{PhD}^{1}$; Weiming Zhu, MD, $\mathrm{PhD}^{1}$; Ya-lin A. Huang, $\mathrm{PhD}^{1}$; Ashley Townes, $\mathrm{PhD}^{2}$; Kevin P. Delaney, PhD ${ }^{1}$; Karen W. Hoover, MD ${ }^{1}$
}

HIV testing is a critical component of effective HIV prevention and care. CDC recommends routine opt-out HIV testing in health care settings for all sexually active persons aged 13-64 years at least once in their lifetime and risk-based testing regardless of age for those who report behaviors associated with HIV acquisition (1). However, recent studies show low HIV testing rates in clinical settings; HIV testing rates at visits to physician offices did not increase during 2009-2016 (2). The objective of the current study is to estimate temporal trends in HIV testing among persons with commercial insurance or Medicaid from 2014 through 2019 and describe their demographic characteristics in 2019. Weighted data from the IBM MarketScan Commercial Claims and Encounters database* (commercial insurance) and from the Centers for Medicare $\&$ Medicaid Services (CMS) claims database ${ }^{\dagger}$ (Medicaid) were analyzed to estimate the proportions of persons with commercial insurance or Medicaid who received testing for HIV. Testing rates increased among male and nonpregnant female persons aged $\geq 13$ years with either type of coverage. In 2019, only $4.0 \%$ of those with commercial insurance and $5.5 \%$ of those with Medicaid received testing for HIV. Testing rates were higher among non-Hispanic Black or African American (Black) persons and Hispanic or Latino (Hispanic) persons. Based on mathematical modeling studies, these annual testing rates would need to increase at least threefold and be sustained over several years $(3,4)$ to achieve the Ending the HIV Epidemic (EHE) in the U.S. initiative goal of $\geq 95 \%$ of persons with HIV being aware of their infection by $2025 .{ }^{\S}$ Interventions need to be implemented to increase routine and risk-based HIV testing in clinical settings to higher levels that can help reduce

\footnotetext{
*https://www.ibm.com/products/marketscan-research-databases/databases

$\dagger$ https://www.cms.gov/Research-Statistics-Data-and-Systems/Computer-Data-andSystems/MedicaidDataSourcesGenInfo. Access to this database is by license only.

$\S_{\text {https://www.hiv.gov/federal-response/ending-the-hiv-epidemic/overview }}$
}

disparities in HIV diagnoses between Black and Hispanic persons compared with non-Hispanic White (White) persons (5). Increased HIV testing is essential to achieve the goals of the EHE initiative and reduce disparities in HIV diagnoses; public health should partner with health care systems to implement interventions that support increased testing.

Many factors might be associated with low HIV testing rates for persons across socioeconomic strata, even among those with health care insurance (G). In 2019, the U.S. Department of Health and Human Services launched the EHE initiative that includes four strategic pillars (diagnose, treat, prevent, and respond) to end the HIV epidemic by 2030 . The "diagnose" pillar is intended to achieve diagnosis for all persons with HIV as early as possible, with a goal to detect $\geq 95 \%$ of all infections by 2025. As part of the initiative, CDC funded

\section{INSIDE}

910 Need for Contraceptive Services Among Women of Reproductive Age - 45 Jurisdictions, United States, 2017-2019

916 COVID-19 Surveillance and Investigations in Workplaces - Seattle \& King County, Washington, June 15-November 15, 2020

922 COVID-19 Vaccination Coverage Among Adults United States, December 14, 2020-May 22, 2021

928 COVID-19 Vaccination Coverage and Intent Among Adults Aged 18-39 Years - United States, March-May 2021

935 QuickStats

Continuing Education examination available at https://www.cdc.gov/mmwr/mmwr_continuingEducation.html

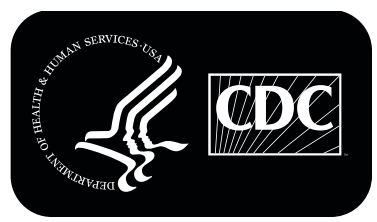


health departments to conduct several activities, including the expansion of routine and risk-based testing in clinical settings. 9 HIV testing can serve as an entry point for HIV prevention and care services and can normalize HIV testing as a routine part of preventive care.

CDC analyzed data from the 2014-2019 MarketScan and Medicaid databases to identify temporal trends in HIV testing in clinical settings among persons with commercial insurance or Medicaid and their demographic characteristics. The MarketScan database is a convenience sample of commercial health plans that include health service information for approximately 40 million persons per year and is weighted using validated methods to be nationally representative of the 200 million U.S. persons with commercial insurance. The CMS database includes information on persons with Medicaid in all 50 states and the District of Columbia. Both databases contained deidentified patient information and diagnostic, procedural, and drug codes for clinical services provided; Medicaid reports data on race/ethnicity, and MarketScan does not. Separate analyses were conducted using the MarketScan and Medicaid databases. Eligibility criteria included persons who 1 ) were aged $\geq 13$ years, 2 ) were continuously enrolled for at least 6 months in a given year, and 3) had no previous HIV diagnosis. Pregnant adolescents and women were excluded because CDC recommends that they receive prenatal testing

\footnotetext{
https://www.cdc.gov/hiv/funding/announcements/ps20-2010/index.html
}

for HIV during each pregnancy, rather than routine or riskbased testing (1). Persons aged $\geq 65$ years were included because HIV prevalence has increased in the oldest age group for which surveillance data are reported (7). HIV diagnoses were identified using codes from the ninth and tenth revisions of the International Classification of Diseases.** $\mathrm{HIV}$ tests were identified using Current Procedural Terminology ${ }^{\dagger \dagger}$ and Healthcare Common Procedure Coding System $\$ \$$ codes. SAS software (version 9.4; SAS Institute) was used to conduct analyses. This activity was reviewed by $\mathrm{CDC}$ and was conducted consistent with applicable federal law and CDC policy. 99

The proportions of male and nonpregnant female persons aged $\geq 13$ years with commercial insurance or Medicaid who received HIV testing each year were estimated. Race/ethnicity data were available only for persons with Medicaid, therefore the trend in testing over time was estimated by race/ethnicity

** International Classifications of Diseases, Ninth Revision (ICD-9) diagnosis codes of $042,079.53,795.71$ were used to identify persons with an HIV diagnosis. https://www.cdc.gov/nchs/icd/icd9.htm. International Classifications of Diseases, Tenth Revision (ICD-10 diagnosis codes of B20, B97.35, O98.7XX, R75, V08, Z21 were used to identify persons with an HIV diagnosis. https:// www.cdc.gov/nchs/icd/icd10.htm

$\dagger \dagger$ Current Procedural Terminology codes 86689, 86701-86703, and 8738987391 were used to identify HIV testing procedures. https://www.ama-assn. org/practice-management/cpt

$\$ \$$ Healthcare Common Procedure Coding System codes G0432-G0435 were also included to identify HIV testing. https://www.cms.gov/Medicare/Coding/ MedHCPCSGenInfo

9945 C.F.R. part 46, 21 C.F.R. part 56; 42 U.S.C. Sect. 241 (d); 5 U.S.C. Sect. 552a; 44 U.S.C. Sect. 3501 et seq.

The MMWR series of publications is published by the Center for Surveillance, Epidemiology, and Laboratory Services, Centers for Disease Control and Prevention (CDC), U.S. Department of Health and Human Services, Atlanta, GA 30329-4027.

Suggested citation: [Author names; first three, then et al., if more than six.] [Report title]. MMWR Morb Mortal Wkly Rep 2021;70:[inclusive page numbers].

\section{Centers for Disease Control and Prevention \\ Rochelle P. Walensky, MD, MPH, Director \\ Anne Schuchat, MD, Principal Deputy Director \\ Daniel B. Jernigan, MD, MPH, Acting Deputy Director for Public Health Science and Surveillance \\ Rebecca Bunnell, PhD, MEd, Director, Office of Science \\ Jennifer Layden, MD, PhD, Deputy Director, Office of Science \\ Michael F. Iademarco, MD, MPH, Director, Center for Surveillance, Epidemiology, and Laboratory Services}

MMWR Editorial and Production Staff (Weekly)

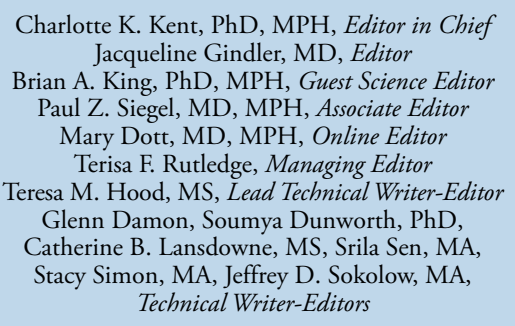
Technical Writer-Editors

Matthew L. Boulton, MD, MPH

Carolyn Brooks, ScD, MA

Jay C. Butler, MD

Virginia A. Caine, MD

Jonathan E. Fielding, MD, MPH, MBA

David W. Fleming, MD
Martha F. Boyd, Lead Visual Information Specialist
Alexander J. Gottardy, Maureen A. Leahy,
Julia C. Martinroe, Stephen R. Spriggs, Tong Yang, Visual Information Specialists
Quang M. Doan, MBA, Phyllis H. King,
Terraye M. Starr, Moua Yang,
Information Technology Specialists

Ian Branam, MA, Ginger Redmon, MA Co-Acting Lead Health Communication Specialist. Shelton Bartley, MPH,

Lowery Johnson, Amanda Ray,

Jacqueline N. Sanchez, MS,

Health Communication Specialists Will Yang, MA,

Visual Information Specialist

\section{MMWR Editorial Board}

Timothy F. Jones, MD, Chairman

William E. Halperin, MD, DrPH, MPH

Christopher M. Jones, PharmD, DrPH, MPH

Jewel Mullen, MD, MPH, MPA

Jeff Niederdeppe, $\mathrm{PhD}$

Celeste Philip, MD, MPH

Patricia Quinlisk, MD, MPH
Patrick L. Remington, MD, MPH

Carlos Roig, MS, MA

William Schaffner, MD

Nathaniel Smith, MD, MPH

Morgan Bobb Swanson, BS 
only for those with Medicaid. The estimated annual percentage change and 95\% confidence intervals were calculated for each trend. The estimated number and proportion of persons with commercial insurance and with Medicaid who had testing in 2019 were stratified by sex, age group, race/ethnicity (Medicaid only), urban versus rural residence, and U.S. Census region.

During 2014-2019, the proportion of male and nonpregnant female persons aged $\geq 13$ years with HIV testing increased an estimated $6.0 \%$ per year among those with commercial insurance, and an estimated 3.2\% among those with Medicaid (Table 1). Among persons with Medicaid, this trend was observed for all racial and ethnic groups except Hispanic persons (Figure). Despite the increase in HIV testing, only $4.0 \%$ of persons with commercial insurance and $5.5 \%$ of persons with Medicaid received testing for HIV in 2019 (Table 1). The proportion of persons with HIV testing was higher among those with Medicaid than among those with commercial insurance across all regions and all demographic groups except persons aged $\geq 65$ years (Table 2). In 2019, among persons with Medicaid, the percentages of Black persons $(8.5 \%)$ and Hispanic persons (5.9\%) with HIV testing were higher than the percentages of White persons (3.9\%) and non-Hispanic Asian (Asian) persons (5.0\%) with HIV testing.

\section{Discussion}

HIV testing rates increased from 2014 through 2019 among persons with commercial insurance and persons with Medicaid. The proportion of persons who received HIV testing was higher among those with Medicaid than among those with commercial insurance; trends were generally similar across demographic characteristics.

Higher rates of HIV testing were expected among persons with Medicaid because Medicaid includes large proportions of persons in populations with the highest rates of HIV diagnoses. A recent study found that from 2009 to 2014 HIV testing increased in community health centers, and this trend likely continued during the period of this study (2). Guidelines for routine opt-out and risk-based HIV testing have been widely disseminated, and testing campaigns have been conducted by public health organizations and health care systems to increase provider awareness of these recommendations. Testing also might have increased as HIV preexposure prophylaxis (PrEP)

FIGURE. Percentage of male and nonpregnant female persons aged $\geq 13$ years with Medicaid who received testing for HIV, by race and ethnicity* - Centers for Medicare \& Medicaid Services, United States, 2014-2019

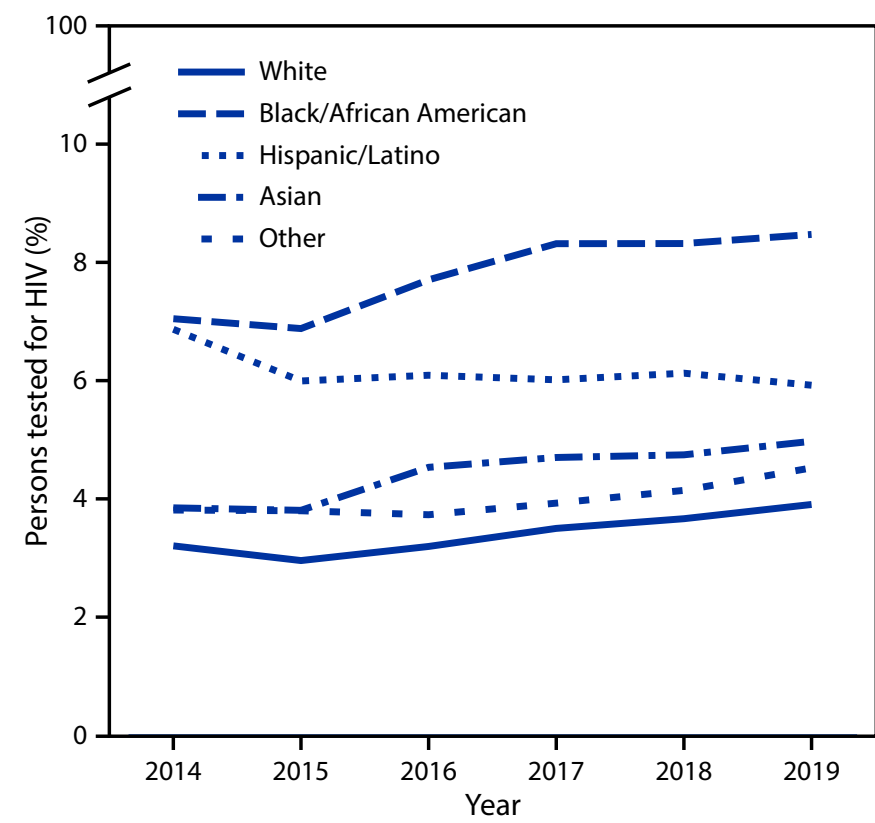

* Persons reported as White, Black, Asian, and Other were non-Hispanic; persons reported as Hispanic/Latino could be of any race.

TABLE 1. Number and percentage of male and nonpregnant female persons aged $\geq 13$ years who received testing for HIV and the estimated annual percentage change in HIV testing among persons with commercial insurance or Medicaid — United States, 2014-2019

\begin{tabular}{|c|c|c|c|c|c|c|c|}
\hline \multirow{2}{*}{$\begin{array}{l}\text { Insurance type/ } \\
\text { Insured persons }\end{array}$} & \multicolumn{6}{|c|}{ Year } & \multirow[b]{2}{*}{$\operatorname{EAPC}^{*}(95 \% \mathrm{Cl})$} \\
\hline & 2014 & 2015 & 2016 & 2017 & 2018 & 2019 & \\
\hline \multicolumn{8}{|l|}{ Commercial $^{\dagger}$} \\
\hline Unweighted no. & $32,965,590$ & $19,983,855$ & $19,897,709$ & $18,747,383$ & $19,122,236$ & $17,471,826$ & N/A \\
\hline Weighted no. ${ }^{\S}$ & $110,689,206$ & $117,747,637$ & $112,914,294$ & $115,710,035$ & $114,177,141$ & $114,726,222$ & $N / A$ \\
\hline Weighted no. with HIV test ${ }^{\S}$ & $3,486,360$ & $3,540,501$ & $3,408,869$ & $3,781,412$ & $4,247,939$ & $4,637,964$ & $6.4(6.3-6.4)$ \\
\hline Weighted \% with HIV test & 3.1 & 3.0 & 3.0 & 3.3 & 3.7 & 4.0 & $6.0(6.0-6.1)$ \\
\hline \multicolumn{8}{|l|}{ Medicaid $^{\dagger}$} \\
\hline Total no. & $45,964,636$ & $51,684,583$ & $52,911,975$ & $53,444,150$ & $53,126,192$ & $52,472,143$ & N/A \\
\hline No. with HIV test & $2,284,238$ & $2,371,188$ & $2,606,385$ & $2,794,386$ & $2,844,232$ & $2,898,425$ & $5.2(5.2-5.2)$ \\
\hline$\%$ with HIV test & 5.0 & 4.6 & 4.9 & 5.2 & 5.4 & 5.5 & $3.2(3.1-3.2)$ \\
\hline
\end{tabular}

Abbreviations: $\mathrm{Cl}=$ confidence interval; $\mathrm{EAPC}=$ estimated annual percentage change; $\mathrm{N} / \mathrm{A}=$ not applicable.

* EAPCs were calculated using a generalized Poisson model.

$\dagger$ Persons who were continuously insured for at least 6 months in a given year.

$\S$ Weighted to generate nationally representative estimates of persons with commercial insurance (https://www.ibm.com/products/marketscan-research-databases/databases). 
use increased during the same period because PrEP users should receive HIV testing at PrEP initiation and every 3 months thereafter $(7,8)$. HIV testing is a strategic priority of EHE and was included among Medicaid noncore health care quality measures for adults in 2021 (9), which could contribute to future increases in HIV testing rates.

The findings in this report are subject to at least four limitations. First, only persons with 6 months of continuous commercial insurance or Medicaid enrollment were included, which might have resulted in an underestimate or overestimate of testing rates. Length of enrollment might vary by a person's demographic characteristics and result in under- or overestimation of HIV testing rates by these characteristics. Second, because there was no link between persons included in the
MarketScan and Medicaid databases, accounting for persons enrolled in both Medicaid and commercial insurance in the same year was not possible. This circumstance might have resulted in counting a person as having been tested in both the commercial insurance and Medicaid analyses in the same year. However, by limiting the analyses to persons enrolled in their health plan for at least 6 months, it is unlikely that many such persons were included in analyses for both systems. Third, Medicare recipients who were not dually enrolled in Medicaid or commercial insurance were not included, so this study included only limited HIV testing information for persons aged $\geq 65$ years. Finally, persons receiving testing at an HIV outreach event or in a venue that did not bill a person's health insurance for the HIV test would not have been included in this study.

TABLE 2. Number and percentage of male and nonpregnant female persons aged $\geq 13$ years with commercial insurance or Medicaid who received testing for HIV, by demographic characteristics - United States, 2019

\begin{tabular}{|c|c|c|c|c|c|}
\hline \multirow[b]{3}{*}{ Characteristic } & \multicolumn{5}{|c|}{ Insured persons* } \\
\hline & \multicolumn{3}{|c|}{ Commercial insurance } & \multicolumn{2}{|c|}{ Medicaid } \\
\hline & Unweighted no. & Weighted no. ${ }^{\dagger}$ & $\begin{array}{l}\text { Weighted no. } \\
\text { with HIV test }{ }^{\dagger}(\%)\end{array}$ & No. & No. with HIV test (\%) \\
\hline Total & $17,471,826$ & $114,726,222$ & $4,637,964(4.0)$ & $52,472,143$ & $2,898,425(5.5)$ \\
\hline \multicolumn{6}{|l|}{ Sex at birth } \\
\hline Male & $8,545,670$ & $57,671,191$ & $2,129,687(3.7)$ & $22,869,597$ & $1,084,432(4.7)$ \\
\hline Female & $8,926,156$ & $57,055,031$ & $2,508,276(4.4)$ & $29,602,546$ & $1,813,993(6.1)$ \\
\hline \multicolumn{6}{|l|}{ Age group, yrs } \\
\hline $13-14$ & 614,706 & $4,137,555$ & $17,427(0.4)$ & $3,550,836$ & $34,672(1.0)$ \\
\hline $15-18$ & $1,144,235$ & $7,924,306$ & $173,427(2.2)$ & $6,272,678$ & $279,257(4.5)$ \\
\hline $19-29$ & $3,600,398$ & $22,265,021$ & $1,515,024(6.8)$ & $10,011,887$ & $855,013(8.5)$ \\
\hline $30-49$ & $6,650,691$ & $45,192,213$ & $2,103,739(4.7)$ & $14,950,792$ & $1,140,752(7.6)$ \\
\hline $50-64$ & $5,448,381$ & $35,119,257$ & $827,531(2.4)$ & $9,816,896$ & $529,234(5.4)$ \\
\hline$\geq 65$ & 13,415 & 87,870 & $816(0.9)$ & $7,869,054$ & $59,497(0.8)$ \\
\hline \multicolumn{6}{|l|}{ Race/Ethnicity } \\
\hline White & -§ & - & - & $19,713,421$ & 769,135 (3.9) \\
\hline Black/African American & - & - & - & $9,283,337$ & $785,673(8.5)$ \\
\hline Hispanic/Latino" & - & - & - & $11,379,127$ & $673,073(5.9)$ \\
\hline Asian & - & - & - & $2,636,311$ & $130,950(5.0)$ \\
\hline Other ${ }^{* *}$ & - & - & - & $1,012,462$ & $45,751(4.5)$ \\
\hline Unknown & - & - & - & $8,447,485$ & $493,843(5.8)$ \\
\hline \multicolumn{6}{|l|}{ Urban/Rural residence $^{\dagger \dagger}$} \\
\hline Urban & $13,853,880$ & $94,995,029$ & $4,195,184(4.4)$ & $41,294,013$ & $2,503,400(6.1)$ \\
\hline Rural & $1,867,957$ & $11,658,371$ & $204,827(1.8)$ & $9,747,177$ & $292,824(3.0)$ \\
\hline Unknown & $1,749,989$ & $8,072,823$ & $237,952(2.9)$ & $1,430,953$ & $102,201(7.1)$ \\
\hline \multicolumn{6}{|l|}{ U.S. Census region ${ }^{\S \S}$} \\
\hline Northeast & $3,199,361$ & $20,951,646$ & $1,204,664(5.7)$ & $10,228,160$ & $732,846(7.2)$ \\
\hline Midwest & $3,492,100$ & $25,925,386$ & $707,469(2.7)$ & $9,274,664$ & $468,835(5.1)$ \\
\hline South & $7,916,680$ & $41,356,545$ & $1,646,199(4.0)$ & $15,431,589$ & 710,537 (4.6) \\
\hline West & $2,801,976$ & $26,430,883$ & $1,076,942(4.1)$ & $16,444,186$ & $923,992(5.6)$ \\
\hline Unknown & 61,709 & 61,762 & $2,690(4.4)$ & $1,094,450$ & $62,222(5.7)$ \\
\hline
\end{tabular}

\footnotetext{
* Persons who were continuously enrolled in their health insurance plan for $\geq 6$ months in 2019.

† Weighted to generate nationally representative estimates of persons with commercial insurance (https://www.ibm.com/products/marketscan-research-databases/databases).

$\S$ Dashes indicate race/ethnicity data not available in commercial insurance data set.

"Race/ethnicity groups are mutually exclusive. Hispanic/Latino persons can be of any race.

** "Other" includes American Indian or Alaska Native and Native Hawaiian or Other Pacific Islander.

${ }^{+\dagger}$ Location of patient residence. For persons with commercial insurance, their urban or rural residence was defined using Metropolitan Statistical Areas codes. For persons with Medicaid, their urban or rural location was defined using their zip code and the Centers for Medicare \& Medicaid Services carriers'Medicare Administrative Contractors and localities files (https://www.cms.gov/Medicare/Medicare-Fee-for-Service-Payment/FeeScheduleGenInfo).

$\S \S$ Northeast: Connecticut, Maine, Massachusetts, New Hampshire, New Jersey, New York, Pennsylvania, Rhode Island, and Vermont. Midwest: Illinois, Indiana, lowa, Kansas, Michigan, Minnesota, Missouri, Nebraska, North Dakota, Ohio, South Dakota, and Wisconsin. South: Alabama, Arkansas, Delaware, District of Columbia, Florida, Georgia, Kentucky, Louisiana, Maryland, Mississippi, North Carolina, Oklahoma, South Carolina, Tennessee, Texas, Virginia, and West Virginia. West: Alaska, Arizona, California, Colorado, Hawaii, Idaho, Montana, Nevada, New Mexico, Oregon, Utah, Washington, and Wyoming.
} 


\section{Summary}

What is already known about this topic?

HIV testing in clinical settings provides an entry point for other HIV care and prevention services.

What is added by this report?

The percentage of males and nonpregnant females aged $\geq 13$ years with either commercial insurance or Medicaid who received testing for HIV increased from 2014 to 2019 but was less than $6 \%$. Testing rates were higher among persons with Medicaid than those with commercial insurance; among those with Medicaid, rates for Black/African Americans and Hispanic/ Latino persons were higher than for White persons.

What are implications for public health practice?

Increasing HIV testing in clinical settings by at least threefold is essential to achieve the goal of $\geq 95 \%$ of persons with HIV being aware of their infection by 2025 and to reduce disparities in HIV diagnoses.

HIV testing rates were highest among Black persons and Hispanic persons, which is encouraging. To accomplish goals of the EHE initiative and to reduce disparities in HIV diagnoses, higher HIV testing rates are needed for all groups, but especially for some racial and ethnic minority groups (4). A recent study found that a two- to threefold increase in HIV testing rates at ambulatory care visits would result in almost all Black men and Hispanic men receiving testing by age 39 years (3). In another recent study, a standing order for a routine opt-out HIV test added to all blood draws in a large health care system in 2016 resulted in $35.4 \%$ of the patient population receiving an HIV test (10). These percentages were much higher than the national percentages found in the current study $(4.0 \%$ among persons with commercial insurance and $5.5 \%$ among those with Medicaid). A recent review conducted by the Community Preventive Services Task Force (CPSTF) found that testing can be efficiently increased at clinical visits by incorporating clinical decision support tools in electronic health records that generate an automated order for routine opt-out testing or risk-based testing (5). Increased HIV testing in clinical settings is essential to achieve the goals of the EHE initiative and reduce disparities in HIV diagnoses. Public health should partner with health care systems to implement interventions, such as those reviewed by the CPSTF, that support increased testing.
Corresponding author: Kirk D. Henny, khenny@cdc.gov, 404-639-5383.

${ }^{1}$ Division of HIV Prevention, National Center for HIV/AIDS, Viral Hepatitis, STD, and TB Prevention, CDC; ${ }^{2}$ Oak Ridge Institute for Science and Education, Oak Ridge, Tennessee.

All authors have completed and submitted the International Committee of Medical Journal Editors form for disclosure of potential conflicts of interest. No potential conflicts of interest were disclosed.

\section{References}

1. Branson BM, Handsfield HH, Lampe MA, et al.; CDC. Revised recommendations for HIV testing of adults, adolescents, and pregnant women in health-care settings. MMWR Recomm Rep 2006;55(No. RR-14). PMID:16988643

2. Hoover KW, Huang YA, Tanner ML, et al. HIV Testing trends at visits to physician offices, community health centers, and emergency departments-United States, 2009-2017. MMWR Morb Mortal Wkly Rep 2020;69:776-80. PMID:32584800 https://doi.org/10.15585/ mmwr.mm6925a2

3. Hoover KW, Khalil GM, Cadwell BL, Rose CE, Peters PJ. Benchmarks for HIV testing: what is needed to achieve universal testing coverage at U.S. ambulatory healthcare facilities. J Acquir Immune Defic Syndr 2021;86:e48-53. PMID:33136820 https://doi.org/10.1097/ QAI.0000000000002553

4. Jenness SM, Johnson JA, Hoover KW, Smith DK, Delaney KP. Modeling an integrated HIV prevention and care continuum to achieve the Ending the HIV Epidemic goals. AIDS 2020;34:2103-13. PMID:32910062 https://doi.org/10.1097/QAD.0000000000002681

5. Community Preventative Services Task Force. HIV prevention: clinical decision support system to increase HIV screening. Atlanta, GA: US Department of Health and Human Services, CDC, The Community Guide. Accessed June 21, 2021. https://www.thecommunityguide.org/ findings/hiv-prevention-and-control-clinical-decision-support-systemincrease-hiv-screening

6. Wise JM, Ott C, Azuero A, et al. Barriers to HIV testing: patient and provider perspectives in the deep South. AIDS Behav 2019;23:1062-72. PMID:30607759 https://doi.org/10.1007/s10461-018-02385-5

7. US Department of Health and Human Services. AHEAD America's HIV epidemic analysis dashboard. Washington, DC: US Department of Health and Human Services; 2021. Accessed June 21, 2021. https:// ahead.hiv.gov

8. Huang YA, Zhu W, Smith DK, Harris N, Hoover KW. HIV preexposure prophylaxis, by race and ethnicity-United States, 2014-2016. MMWR Morb Mortal Wkly Rep 2018;67:1147-50. PMID:30335734 https:// doi.org/10.15585/mmwr.mm6741a3

9. Centers for Medicare \& Medicaid Services. Quality of care performance measurement. Baltimore, MD: Centers for Medicare \& Medicaid Services; 2021. Accessed April 28, 2021. https://www.medicaid.gov/ medicaid/quality-of-care/quality-of-care-performance-measurement/ index.html

10. Arya M, Marren RE, Marek HG, Pasalar S, Hemmige V, Giordano TP. Success of supplementing national HIV testing recommendations with a local initiative in a large health care system in the U.S. South. J Acquir Immune Defic Syndr 2020;83:e6-9. PMID:31929408 https:// doi.org/10.1097/QAI.0000000000002222 